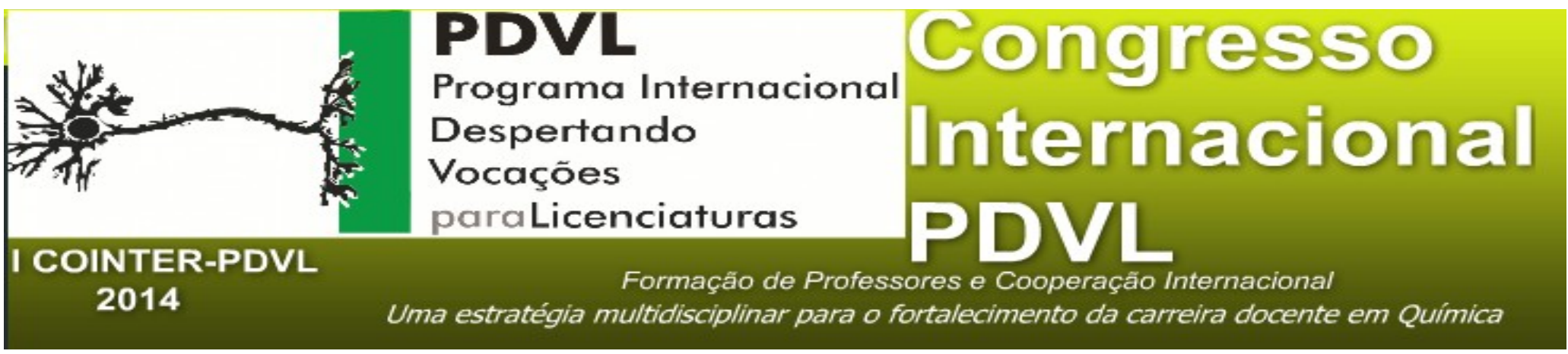

\title{
A EXPERIMENTAÇÃO DEMONSTRATIVA COMO RECURSO DIDÁTICO PEDAGÓGICO NAS AULAS DE QUÍMICA GERAL
}

Apresentação: Pôster

Ana Paula Ferreira da Silva ${ }^{1}$; Wlisses Guimarães Souza ${ }^{2}$; Claúdio Henrique Alves Perdigão ${ }^{3}$

\section{Introdução}

O nível de abstração inerente do conteúdo intitulado "Modelos atômicos” é um fator de dificuldade encontrada pelos alunos, tal abstração evolui exponencialmente seguindo a cronologia de tais modelos desde o simplório modelo atômico de Dalton (1808), que conseguiu justificar as leis ponderais e volumétricas, seguido pelo modelo de J. J. Thomson (1897) o qual fez menção a natureza elétrica da matéria; no entanto, a característica de descontinuidade atômica (em oposição a seu aspecto maciço) se deu por meio do "modelo planetário" apresentado em 1911 por Ernest Rutherford (discípulo de Thomson). Porém, bastaram apenas dois anos para que o físico dinamarquês, Niels Bohr, à luz da teoria quântica, interpretasse algumas das propriedades das séries espectrais do hidrogênio e a estrutura do sistema periódico dos elementos para elucidar a estrutura atômica. A transposição didática de tal teoria elevou consideravelmente o nível de abstração exigido para sua compreensão plena em sala de aula. Assim, nosso trabalho objetivou

1 Licenciatura em Química/Instituto Federal de Educação, Ciências e Tecnologia de Pernambuco/ Pibid/ paulinhaah16@hotmail.com

2 Professor Instituto Federal de Pernambuco/wlisses.guimaraes@vitoria.ifpe.edu.br

3 Professor Instituto Federal de Pernambuco/claudio.perdigao@vitoria.ifpe.edu.br 
buscar na abordagem da experimentação demonstrativa uma alternativa didática para o aprendizado significativo da teoria atômica de Bohr.

\section{Fundamentação Teórica}

A concepção inadequada de modelo em sala de aula é observada tanto nos alunos (MASKILL e JESUS, 1997) quanto nos professores atuantes e em formação (MELO, 2002).

Partindo do preconizado nos Parâmetros Curriculares Nacionais (PCNs) todo experimento deve ser o ponto inicial para que os alunos discutam, especulem, construam e reconstruam o significado dos seus conhecimentos (Brasil, 2000), as aulas deverão promover uma relação íntima de ensino-aprendizagem, sem deixar de lado todo fundo teórico que precisa ser visto, para que não se tornem apenas aulas divertidas enfatizando uma visão pictórica da Química. Mas que essa metodologia propicie o conhecimento, pois as práticas sem privilégios aos aspectos cognitivos não contribuem para desenvolvimentos de conceitos químicos, podendo levar a formação de um indivíduo sem a capacidade de argumentar, reproduzindo apenas o que lhe foi transmitido.

As atividades experimentais propostas para que o estudante participe ativamente dos processos de coleta de dados, análise, discussão, ou seja, planejadas com o objetivo de explorar as suas habilidades cognitivas - como, por exemplo, desenvolvimento da capacidade de identificar e estabelecer processos de controle e seleção de informações relevantes para a solução do problema; identificação de variáveis; elaboração de hipóteses, entre outras - podem contribuir para o desenvolvimento do raciocínio lógico dos alunos em busca da construção do conhecimento químico (GIL-PÉREZ E VALDÉS CASTRO,1996; Domin, 1999; Hodson, 2005).

\section{Metodologia}

O campo de atuação do Projeto é o IFPE - Instituto Federal de Educação Ciência e Tecnologia de Pernambuco, que oferece o Ensino médio técnico, nas modalidades: concomitante e subsequente. Onde teve como população/amostra professores do ensino médio que atuam na disciplina de química e alunos de todas as turmas do primeiro ano do ensino médio, de agropecuária e agroindústrias.

O projeto fez referência aos três momentos pedagógicos. Segundo (CHAVES E PIMENTEL, 1997) o primeiro, denominado Problematização Inicial (PI), consiste em apresentar questões problematizadoras com o intuito de discutir os conhecimentos prévios dos alunos. A Organização do Conhecimento (OC) é o momento pedagógico em que as propostas apresentadas durante a problematização inicial começam a ser decifradas por meio dos conhecimentos 
científicos. Por fim, a Aplicação do Conhecimento (AC) trata da reinterpretação da PI e da transposição para situações do cotidiano.

Nossa intervenção didática iniciou por uma avaliação diagnóstica para que pudéssemos analisando os dados coletados, constatar (ou refutar) a evolução na aprendizagem dos discentes. Durante o procedimento experimental os estudantes foram motivados a participar de forma ativa, elaborando hipóteses e propondo possíveis soluções referentes a aplicabilidade e contextualização do "teste de chama", bem como, pela correlação ao modelo atômico de Bohr. Vale ressaltar que selecionamos sais que possuíssem cátions importantes para o tecnolando do curso de agropecuária e agroindústria. A medida que aspergimos as respectivas soluções salinas sob chama alcóolica, cada aluno preenchia a Tabela 1 abaixo e em seguida pela análise da tabela foi perguntado qual espécie química (cátion ou ânion) o teste de chama consegue identificar (pergunta 1).

Tabela 1:

\begin{tabular}{|c|c|c|c|c|}
\hline Sal & $\mathrm{NaCl}$ & $\mathrm{CaCl}_{2}$ & $\mathrm{KCl}$ & $\mathrm{CuSO}_{4}$ \\
\hline $\begin{array}{c}\text { Cor } \\
\text { da chama }\end{array}$ & & & & \\
\hline
\end{tabular}

A segunda pergunta versou sobre qual cor seria revelado na chama caso o elemento químico testado emitisse luz visível com $440 \mathrm{~nm}$ de comprimento. Como suporte analítico, dispomos uma figura do espectro contínuo da luz solar associando a cor da chama ao respectivo comprimento de onda (pergunta 2). A última questão foi: O sal de cozinha emite luz de coloração amarela quando colocado numa chama. Baseando-se na teoria atômica, é correto afirmar que: a) Os elétrons do cátion $\mathrm{Na}^{+}$, ao receber energia da chama, saltam de uma camada mais externa para uma mais interna, emitindo luz amarela. b) A luz amarela emitida nada tem a ver com o sal de cozinha pois ele não é amarelo. c) A emissão da luz amarela se deve ao átomo de oxigênio. d) Os elétrons do cátion $\mathrm{Na}^{+}$, ao receberem energia da chama saltam de uma camada mais interna para uma mais externa, ao perderem a energia ganha, emitem-na sob a forma de luz amarela. (pergunta 3).

\section{Resultados e Discussão}

No presente experimento do Teste da Chama privilegiou-se a análise qualitativa do registro escrito dos alunos, tendo em vista as alterações ocorridas no sistema a partir da ficha de observação experimental. De posse dos resultados coletados (plotados no Gráfico 1), em relação a pergunta 1, percebemos que grande maioria dos alunos assimilou corretamente a finalidade do teste de chama: identificação dos cátions. Na pergunta 2 objetivamos que os discentes pudessem prever a coloração da chama alcóolica, fazendo uso da experimentação simulada, no tocante a pergunta 3 os alunos 
conseguiram, em sua grande maioria (37 alunos) associar o conhecimento fenomenológico (coloração amarela do $\mathrm{NaCl}$ sob a chama) ao conhecimento teórico (teoria da energia quantizada).

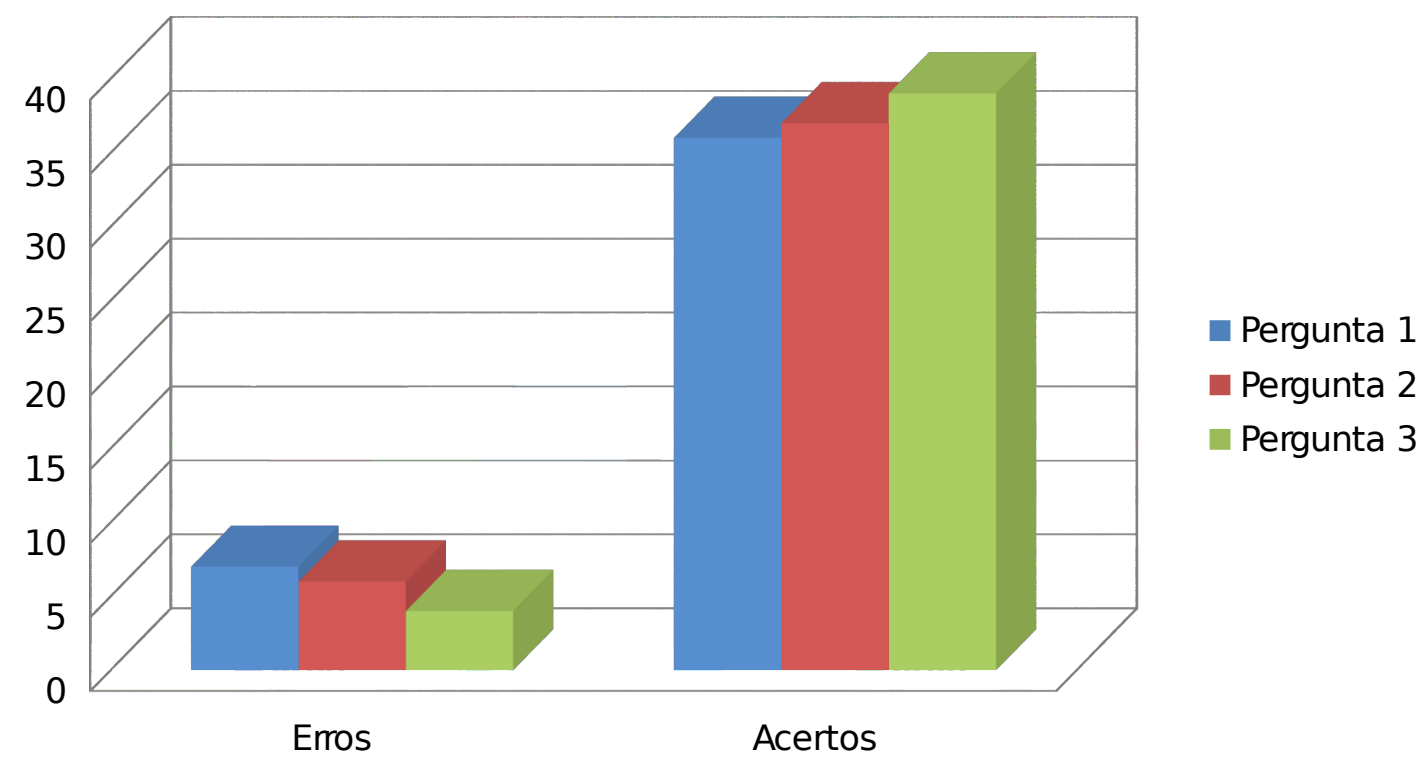

Gráfico 1. Quantitativo de erros e acertos às perguntas propostas do teste de sondagem.

\section{Conclusões}

A análise dos resultados revelou que a experimentação demonstrativa proposta mediou a aprendizagem significativa do conteúdo "Modelo atômico de Bohr” pela condução concomitantemente problematizada do tema. Esse é o papel motivador da experimentação: mediatizar os educandos e o objeto cognoscitivo. Concluímos que aprendizagem significativa poderá ser alcançada pela observação macroscópica dos fenômenos em justificativa as teorias socialmente e constantemente concebidas historicamente nas Ciências Naturais, em particular, na Química.

\section{Referências}

BRASIL. Lei de Diretrizes e Bases da Educação. Brasília: MEC, 1996, Ministério da Educação. Secretaria de Educação Básica. Parâmetros Curriculares Nacionais: ciências da natureza, matemática e suas tecnologias. Brasília: 2000.

MEC, 1996JÚNIOR, W.E.F. Et Al (2008); Uma abordagem Problematizadora para o Ensino de Interações Moleculáres e conceitos afins. In: Química Nova na Escola. n. 29, p. 20-23 
SCHWAHN, M.C.A e OAIGEN, E.R (2009); Objetivos para o Uso da Experimentação no Ensino de Química: A visão de um grupo de Licenciandos. In VII Encontro Nacional de Pesquisa em Educação em Ciência. Florianópolis, ES.

GIL-PEREZ, D. e VALDÉS CASTRO, P. (1996) La orientacion de Las Prácticas de Laboratório com Investigacion: Um Ejemplo Ilustrativo. Enseñanza de Las Ciências, 14(2), p.155-163, 1996.

MASKILL, R. e JESUS, H. P. Asking model questions. Education in Chemitry, v. 32, n 5 p. 132-134, 1997.

MELO, M. R. Estrutura atômica e ligações químicas- uma abordagem para o ensino de médio. 2002. Dissertação (mestrado)- Universidade Estadual de Campinas, Campinas, 2002

DOMIN, D. S. (1999) A Review of Laboratory Instruction Styles. Journal of Chemical Education. 76 (4), april, p. 543-7.

HODSON, D. (2005) Teaching and Learning Chemistry in the Laboratory: A Critical Look at the Research. Educación Química, 16(1), p.30-38. 